\title{
Metformin and Malignant Tumors: Not Over the Hill
}

\begin{abstract}
Weiling Leng, ', Juan Jiang, ${ }^{2, *}$ Bing Chen,' Qinan Wu $\mathbb{D}^{3}$

'Endocrinology Department, The First Affiliated Hospital of the Third Military Medical University (Army Medical University), Chongqing, People's Republic of China; ${ }^{2}$ Endocrinology and Nephrology Department, Chongqing University Cancer Hospital and Chongqing Cancer Institute and Chongqing Cancer Hospital, Chongqing, People's Republic of China; ${ }^{3}$ Endocrinology Department, Dazu Hospital of Chongqing Medical University, The People's Hospital of Dazu, Chongqing, People's Republic of China

*These authors contributed equally to this work
\end{abstract} Video abstract

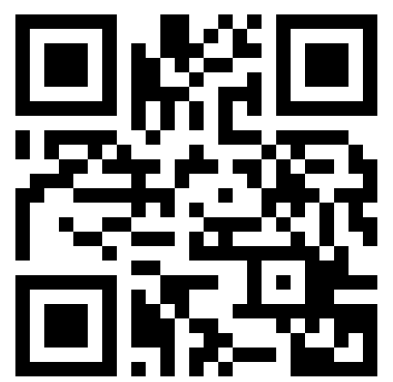

Point your SmartPhone at the code above. If you have a $Q R$ code reader the video abstract will appear. Or use: https://youtu.be/MWKNn8872gg

Correspondence: Qinan Wu Endocrinology Department, Dazu Hospital of Chongqing Medical University, The People's Hospital of Dazu, Chongqing, People's Republic of China Email wqnII@I26.com

Bing Chen

Endocrinology Department, The First Affiliated Hospital of the Third Military Medical University (Army Medical

University), Chongqing, People's Republic of China

Email chenbingxnyy@I26.com

\begin{abstract}
Malignant tumors are a major cause of death, and their incidence is increasing worldwide. Although the survival rate for some cancers has improved, treatments for other malignant tumors are limited, and their mortality rate continues to increase. People with type 2 diabetes have a higher risk of malignant tumors and a higher mortality rate than those without diabetes. Metformin is a commonly used hypoglycemic drug. In recent years, a growing number of studies have indicated that metformin has antitumor effects and increases the sensitivity of malignant tumors to chemotherapy. However, the effect of metformin on different tumors is currently controversial, and the mechanism of metformin's antitumor action is not fully understood. Insights into the effect of metformin on malignant tumors and the possible mechanism may contribute to the development of antitumor drugs.
\end{abstract} Keywords: metformin, malignant tumor, type 2 diabetes mellitus, insulin resistance, 5' adenosine monophosphate-activated protein kinase, antitumor

\section{Introduction}

In the 21 st century, noncommunicable diseases, including malignant tumors, are the main causes of death globally, ${ }^{1}$ and malignant tumors are also the most important obstacle to improving life expectancy. The latest global cancer statistics has estimated that there will be 19.29 million new cases of cancer and 9.96 million cancer-related deaths worldwide in 2020 and 4.57 million new cases in China. At present, the cancer prevalence rate in China is the highest in the world. Breast cancer and lung cancer are the most common cancers worldwide, followed by colorectal cancer (10.0\%), prostate cancer (7.3\%) and stomach cancer $(5.6 \%)$. Lung cancer remains the leading cause of cancer-related death, followed by colorectal $(9.4 \%)$, liver $(8.3 \%)$, stomach $(7.7 \%)$, and female breast $(6.9 \%)$ cancers. ${ }^{2}$

Type 2 diabetes mellitus (T2DM) is a group of metabolic diseases with deficiency in insulin secretion and/or insulin sensitivity leading to hyperglycemia.T2DM prevalence is increasing yearly and has become the sixth most common cause of death. ${ }^{3}$ Epidemiological studies have shown that T2DM patients have an increased risk of liver cancer, pancreatic cancer, stomach cancer, colorectal cancer, kidney cancer, breast cancer and other malignant tumors. ${ }^{4}$ Diabetes or hyperglycemia is associated with reduced insulin sensitivity and increased expression of insulin-like growth factor (IGF), which then stimulates the development of cancer. The proliferation of viscera, pancreas and colon cancer cells also increases the risk of malignant tumors. ${ }^{5,6}$ Globally, T2DM is related to an increased burden of malignant tumors, which has aroused interest in defining the epidemiological and biological relationships between T2DM and malignant tumors. ${ }^{3}$ 
Metformin is a hypoglycemic drug that is safe, effective and inexpensive. In addition to its hypoglycemic effects, a growing body of research has indicated that metformin may have other effects: it may improve lipid metabolism and weight loss, reduce cardiovascular incidence, inhibit brain function, slow cognitive decline, and reduce the risk of dementia. ${ }^{7-9}$ In addition, basic and clinical research has indicated that metformin has antitumor effects and enhances sensitivity to chemotherapy. ${ }^{10-12}$ However, current studies have found that the effects of metformin on different tumors are controversial, and the antitumor mechanism of metformin is not completely clear.In this manuscript, the effect of metformin on many malignant tumors and its possible mechanism were reviewed and analyzed.

\section{Effect of Metformin on Malignant Tumors \\ Breast Cancer}

Breast cancer was the most common cancer in 2020, with an estimated 2.26 million new cases $(11.7 \%){ }^{2}$ It is well known that diabetes is a key risk factor for breast cancer, regulating estrogen availability and receptor function, thereby increasing the risk and progression of breast cancer. ${ }^{13}$ Previous research has indicated a lower incidence of invasive breast cancer in diabetic women using metformin ${ }^{14}$ than in women who used other hypoglycemic medications. Then, a growing number of clinical and basic studies demonstrated that metformin reduced the incidence, metastasis and recurrence rate of breast cancer in women. ${ }^{15,16}$ A retrospective cohort study included 14,766 women newly diagnosed with stage I or II breast cancer, 791 of whom experienced secondary breast cancer events, 627 of whom experienced disease relapse, and 237 of whom died of breast cancer. The results showed that metformin use $(n=$ 2558) reduced the risk of secondary breast cancer events, recurrence, and death by $28 \%, 31 \%$, and $49 \%$, respectively. ${ }^{17}$ It was also found that metformin inhibited breast cancer metastasis and reduced chemotherapy resistance in women with breast cancer. Wang JCand colleagues established a mouse model of metastatic breast cancer and compared the lung metastasis and chemosensitivity of metformin-treated and untreated mice. Finally, the authors proposed that metformin reduced the pulmonary metastasis rate of primary tumors and increased sensitivity to chemotherapy, which may be mediated by the vascular effects of metformin. ${ }^{18}$ Currently, most studies of metformin in breast cancer have been based on diabetic patients; ${ }^{19-22}$ however, a randomized, Phase II, double-blind, placebo-controlled trial in 2012 involving breast cancer patients with nondiabetic disease reached a different conclusion. Stage I to IIa breast cancer patients without diabetes were included in the trial; these patients were candidates for elective surgery and received either metformin or placebo for 4 weeks before surgery. ${ }^{23}$ The results showed that metformin before surgery had no significant effect on the overall proliferation of breast cancer, but had an inhibitory effect on the proliferation in the women with increased HOMA index, while the opposite trend was observed in women with normal insulin sensitivity. ${ }^{23}$ In this study, metformin was used only 4 weeks before surgery for a relatively short period of time, and breast cancer progression was affected by confounders such as emotional state and hormones. Further studies are needed to support this view.

Triple-negative breast cancer (TNBC) is a subtype of breast cancer with the lowest five-year survival rate; TNBCis highly invasive and metastasizes readily, and the therapeutic effect against TNBC is poor. ${ }^{24}$ In 2013, Wahdan-Alaswad Ret al demonstrated that metformin promoted the apoptosis and necrosis of breast cancer cells, especially TNBC cells, through reduced IGF-1R expression, but this effect was inhibited with increased glucose concentration. ${ }^{25}$ Since then, the authors further sought to explore the mechanism of metformininduced inhibition of TNBC and proved that metformin induced TNBCcell death and blocked stem cell expansion through the activation of miR-193b, which downregulates fatty acid synthase (FASN). ${ }^{26}$ Wahdan-Alaswad R and colleagues also studied the effects of metformin on the mesenchymal stem-like/claudin-low (MSL/CL)-one subtype of TNBC. The authors found that metformin inhibited the occurrence of MSL/CL breast cancer by suppressing transforming growth factor- $\beta$ (TGF- $\beta$ ) signaling through the inhibition of endogenous Smad 2 and Smad3 in MSL/CL cell lines and weakened the TGF- $\beta$-induced epithelial-to-mesenchymal transition (EMT) through the reduction of Snail expression in MSL/CL cell lines, thus reducing tumor migration and invasion. ${ }^{27}$ Two years later, the authors confirmed that the inhibition of TNBC proliferation by metformin may be related to the inhibition of the cholesterol synthesis pathway. ${ }^{28}$ In addition, Liu B et al studied the effect of metformin on trastuzumab-resistant breast cancer cells. The results showed that metformin inhibited the proliferation of trastuzumab-resistant breast cancer cells by inactivating erbB3 and IGF-1R, reducing complex formation between erbB2 and IGF-1R and inactivating the Src kinase and/or PI-3K/Akt pathway downstream. ${ }^{29}$ At present, however, others hold a different view. In 2019, Chen H et al conducted a retrospective multicenter study to investigate the effects of hypoglycemic agents on the risk of different breast 
cancer subtypes. ${ }^{30}$ Finally, 1992 ER+/HER2- patients, 324 ER +/HER2+ patients, 1446 TNBC patients and 578 HER2+ patients were included for analysis. The study demonstrated that women with T2DM had a $38 \%$ increased risk of TNBC, and the longer metformin was used, the higher the risk of TNBC. ${ }^{30}$ However, this study mainly discussed the risk of different types of breast cancer in diabetic patients, and the effect of metformin on this risk was low.There is no strong evidence that metformin is associated with an increased risk of TNBC.

Currently, many studies have demonstrated that metformin can reduce the risk of breast cancer in diabetic patients. However, there are few studies on the impact of metformin in nondiabetic breast cancer patients and in patients with different types of breast cancer, and there are some controversies; thus, additional clinical studies are needed.

\section{Lung Cancer}

In 2020, lung cancer was the leading cause of cancer-related death and the second most common cancer, representing approximately 1.8 million (18.0\%) cancer-related deaths and 2.2 million (11.4\%) cancers diagnosed. ${ }^{2}$ Diabetes mellitus is a common complication of lung cancer. The recurrence rate of lung cancer patients with diabetes is higher, and the treatment effect is worse than that of nondiabetic lung cancer patients. ${ }^{31}$ Metformin has been researched for many years as an adjuvant treatment for lung cancer. Previous studies have indicated that metformin improves the survival rate of patients with non-small-cell lung cancer (NSCLC) and small cell lung cancer (SCLC). ${ }^{31-36}$ Metformin showed doseresponse relationships with lung cancer incidence and mortality rates, and the rates in participants with reported cumulative daily use of metformin with a cumulative daily dose (cDDD) greater than 547.5 per 2-year interval were significantly higher than those in nondiabetic patients. ${ }^{37}$ Sha Zeng analyzed 10 clinical studies and 4397 subjects for metaanalysis. The results suggested that metformin treatment significantly improved the survival rate of lung cancer patients. The authors also stratified lung cancer subtypes, suggesting overall survival (OS) risk ratios of 0.78 for undifferentiated, 0.73 for NSCLC, and 0.51 for SCLC.$^{38}$ Recently, researchers analyzed the association between metformin use before and after diagnosis and analyzed OS and lung cancerspecific survival (LCSS) in patients with lung cancer. The results found that metformin use before diagnosis was associated with better LCSS in patients with both squamous cell carcinoma and regional squamous cell carcinoma. In all lung cancer patients, especially in patients with squamous cell carcinoma, localized lung cancer, and localized squamous cell carcinoma, the postdiagnosis use of metformin was associated with improvement in LCSS. Similar results were obtained for OS. Cumulative use analysis showed that there was a dose-response relationship among all patients, adenocarcinoma and squamous cell carcinoma patients, and regional and metastatic lung cancer patients. ${ }^{39}$ Both clinical and epidemiological results suggest that metformin reduced the incidence of lung cancer.In vitro studies have demonstrated that metformin inhibited the proliferation and invasion of lung cancer cells by activating PP2A, andPP2A inhibited the activation of the tumor-promoting proteins Bax, myc and Akt mainly by catalytic dephosphorylation. ${ }^{40}$ Both clinical and basic studies have suggested that metformin has a protective effect on lung cancer, which provides a new way to treat lung cancer in the future.

At present, studies on the protective effect of metformin on lung cancer are the largest and most mature, and these studies included different types, stages and drug resistance of lung cancer. A few years ago, a number of hospitals, including our hospital in China, began to use metformin in patients with lung cancer and achieved certain efficacy.Therefore, after the exclusion of contraindications, metformin is expected to be routinely used as adjuvant therapy for lung cancer patients.

\section{Colorectal Cancer}

The colorectal cancer incidence rate ranks third (more than 1.93 million new cases), but the mortality rate ranks second among all malignant tumors $(935,000$ deaths). ${ }^{2}$ There is increasing evidence that patients with T2DM have a higher risk of colorectal cancer and related death. ${ }^{41,42}$ Metformin can reduce the size of colorectal cancer and inhibit its proliferation. In 2004, Yu Xiao Yang et al first suggested a link between metformin and colon cancer. ${ }^{43}$ A cohort study of 47,351 diabetic patients, which minimized time window bias, demonstrated a negative association between the long-term use of metformin and the risk of colorectal cancer, especially in men. ${ }^{44}$ Higurashi $\mathrm{T}$ et al conducted a one-year clinical trial to evaluate the safety and chemoprophylaxis of metformin in sporadic colorectal cancer in patients at high risk for adenoma recurrence. The results revealed that low-dose metformin reduced the incidence and number of metachronous adenomas or polyps after polypectomy, and metformin had a potential role in the chemoprophylaxis of colorectal cancer. ${ }^{45}$ Recently, researchers have suggested that metformin may be helpful for enhancing the 
therapeutic effect of radiotherapy in rectal cancer patients during radiotherapy. ${ }^{46}$ Moreover, the researchers also cocultured three different cancer lines, SW480, HT29 and HCT116, with metformin and administered radiation at the same time to observe cancer cell growth. The authors noted that metformin enhanced the response of tumors to radiation in vivo and in vitro. ${ }^{46}$ This study was mainly conducted in cell and mouse models, and further clinical observational studies are needed to verify this phenomenon.For patients with metastatic colorectal cancer, the OS rate is still poor, especially for patients with KRAS gene mutations, despite the use of irinotecan- or oxaliplatin-based chemotherapy combined with antiepidermal growth factor receptor (EGFR) drugs. Abnormal KRAS signaling plays a critical role in tumor cell proliferation and is usually associated with a poor prognosis and resistance to EGFR therapy. Recently, Chinese researchers indicated that compared with other hypoglycemic drugs combined with standard treatment, metformin selectively inhibits KRAS-mutant metastatic colorectal cancer in patients with diabetes. The median survival time of this group of patients was prolonged by 37.8 months. This significant effect was found in the patient-derived xenograft tumor (PDX) model and a mutant cell model. This study raises the possibility of using metformin to treat patients with metastatic colorectal cancer with KRAS mutations. ${ }^{47}$ This study has verified the protective effect of metformin on patients with metastatic colorectal cancer with KRAS mutations from many aspects in clinical and basic studies. However, this study is a retrospective study with certain limitations, and additional prospective studies are needed to prove the protective mechanism of metformin in colorectal cancer.

Currently, there are many studies on the effect of metformin on colorectal cancer, ranging from precancerous lesions to advanced colorectal cancer, and most studies support the protective effect of metformin on colorectal cancer, although there are a few that support the opposite view.

\section{Prostate Cancer}

Prostate cancer was the second most frequent cancer for males in 2020, with an estimated 1.4 million new cases and 375,000 deaths worldwide. ${ }^{2}$ The effect of metformin on the risk of prostate cancer remains controversial. A meta-analysis indicated that the lower incidence of prostate cancer in T2DM patients may be associated with decreased testosterone levels in uncontrolled diabetes. ${ }^{48}$
Metformin treatment of T2DM may reverse the metabolic conditions that decrease androgen levels, and the resulting increase in androgen levels can stimulate tumor development, growth and proliferation.50 A recent retrospective study also suggested that metformin therapy increased the risk of prostate cancer, which may be associated with genetic variation in metformin metabolism pathways. ${ }^{50}$ However, other studies have suggested that metformin reduces the risk of prostate cancer. In 2013, David Margel and his colleagues reviewed patients newly diagnosed with diabetes aged 66 years and older from January 1997 to March 31, 2008, and the authors compared these patients with patients newly diagnosed with diabetes and prostate cancer in the Ontario Cancer Registry in Canada. The results demonstrated that metformin treatment reduced the disease-specific mortality and all-cause mortality of prostate cancer. ${ }^{51}$ Metformin use reduced the risk of prostate cancer in men with T2DM in Taiwan, ${ }^{52}$ according to a retrospective cohort study. In an in vitro study, Bing Yang et al indicated that metformin after androgen-blockade therapy induced the apoptosis of prostate cancer cells, weakened the activation of mTOR by androgen-blockade therapy, reduced the number of senescent cells in vitro, and inhibited tumor growth in a PDX model of prostate cancer cells. ${ }^{53}$

The androgen receptor (AR) is the first major driver of prostate cancer growth; androgen-deprivation therapy(ADT) is an important treatment for advanced prostate cancer, and AR downregulation is considered a preventive strategy for prostate cancer and prostate cancer recurrence after treatment. ${ }^{54}$ Metformin can abrogate the upregulation of AR via the enhanced activity of the midline-1 (MID1) translational regulator complex and improve the efficacy of ADT. ${ }^{55}$ In addition, metformin can restrain the AR signaling pathway by downregulating the levels of AR mRNAs. ${ }^{56}$ These studies support the potential effects of metformin in combination with ADT therapy. The prospect of metformin as an adjuvant therapy of ADT, external beam radiotherapy, prostatectomy or chemotherapy appears promising. ${ }^{49}$

At present, the relationship between metformin and prostate cancer is still unclear and may be related to the pathogenesis of prostate cancer. Therefore, it is not recommended to use metformin in nondiabetic prostate cancer patients, while metformin can be routinely used in prostate cancer patients with T2DM after the exclusion of contraindications. 


\section{Gastric Cancer}

Gastric cancer was estimated to be the fifth most common cancer and the fourth most common cause of cancerrelated death in 2020.2 Epidemiologicalstudies on the relationship between diabetes and the risk of gastric cancer are inconclusive, and the results are contradictory. ${ }^{57}$ However, studies have suggested that the risk of gastric cancer in patients with T2DM treated with metformin is lower than that in patients without metformin. ${ }^{55,58}$ Tseng $\mathrm{CH}$ indicated that metformin significantly reduced the risk of gastric cancer, especially when the cumulative time of use was more than two years. ${ }^{59}$ The results of Ruiteret al suggested that metformin exposure is generally associated with a lower incidence of cancer, especially gastric cancer, than exposure to sulfonylurea derivatives. ${ }^{60}$ The study also demonstrated that metformin treatment was associated with a lower risk of gastric cancer in a duration-and dosedependent manner in Helicobacter pylori-eradicated diabetic patients. ${ }^{61}$ Choong-kun Leeet al divided 1974 patients with gastric cancer who underwent radical gastrectomy into three groups: diabetic patients who received metformin treatment; diabetic patients who did not receive metformin treatment; and nondiabetic patients. The results indicated that increasing the cumulative time of metformin use can reduce the gastric cancer recurrence rate, the sex specificity of gastric cancer mortality and the all-cause mortality rate. ${ }^{62} \mathrm{Kim}$ et al reported a retrospective study on metformin and the risk of gastric cancer in diabetic patients. Participants aged 40-80 years old from 2002 to 2003 were divided into three groups: diabetic patients using metformin; diabetic patients not using metformin; and nondiabetic patients. The median follow-up time was 12.7 years. The results suggested that the cumulative incidence of gastric cancer was the highest in patients who did not take metformin and the lowest in nondiabetic patients who used metformin. Finally, the researchers noted that diabetic patients who used metformin had a lower risk of gastric cancer. ${ }^{63}$ These clinical studies revealed that metformin reduced the risk of gastric cancer; however, these studies did not indicate whether metformin has a direct anticancer effect. Therefore, the direct effect of metformin on gastric cancer and its potential molecular mechanism need to be further explored. Previous studies have suggested that metformin inhibited the proliferation, growth and metastasis of gastric cancer cells and promoted their apoptosis. Hanet al used metformin to treat three different differentiated gastric cancer cell lines (MKN-28, SGC7901 and BGC-823) and a noncancer gastric cancer cell line (GES-1). The results indicated that metformin treatment selectively induced apoptosis in the three types of cancer cells but not in the noncancer cells, suggesting that metformin-mediated apoptosis is related to the poor differentiation of gastric cancer cells. ${ }^{64}$ Recent studies have suggested that metformin regulates the metabolism of gastric stem cells and promotes their differentiation into gastric parietal cells that produce gastric acid. This study indicated that the AMP-activated protein kinase (AMPK) metabolic pathway promotes the generation of acidsecreting parietal cells from stem cells. Metformin activates AMPK and Kruppel-like factor 4 (KLF4) to slow the proliferation of progenitor cells and activates AMPK and peroxisome proliferator-activated receptor gamma coactivator 1-alpha (PGC-1a) to induce the maturation of parietal cells. These findings indicate why metformin induces the maturation of gastric parietal cells, increasing acid secretion and reducing the risk of gastric cancer, highlighting its potential applications. ${ }^{65}$

In both diabetic and nondiabetic studies, metformin had a protective mechanism for gastric cancer, suggesting that metformin can reduce the risk of gastric cancer by mechanisms other than its hypoglycemic effect. It is suggested that when the conventional treatment of gastric cancer is ineffective, including metformin as adjuvant therapy can be considered.

\section{Liver Cancer}

In 2020, liver cancer was the sixth most common cancer and the third leading cause of cancer-related death in the world. There are approximately 906,000 new cases and 830,000 related deaths every year. ${ }^{2}$ Diabetes is now considered an independent risk factor for liver cancer and has been shown to increase the risk of liver cancer even in those who are not infected with hepatitis B virus (HBV) or hepatitis $\mathrm{C}$ virus(HCV). ${ }^{66}$ Previous studies have suggested a reduced risk of primary liver cancer in men with T2DM who took metformin. ${ }^{67}$ A subsequent gender-related cohort study also showed a decreased risk of primary liver cancer in men with T2DM who took metformin. ${ }^{68}$ A prospective cohort study conducted by Lee MSet al in Taiwan indicated that metformin reduced the risk of primary liver cancer compared with other antidiabetic patients. ${ }^{69}$ The study also suggested that metformin combined with radiotherapy prolonged the OS of patients with primary liver cancer. ${ }^{70}$ In addition, metformin successfully reversed or delayed the occurrence of hepatitis, liver fibrosis, cirrhosis and spontaneous liver cancer caused by streptozotocin (STZ) and N,N-diethylnitrosamine (DEN), 
indicating that metformin had the same effect as chemotherapy. ${ }^{71}$ Most previous studies have shown a significant reduction in the incidence of hepatocellular carcinoma in T2DM patients treated with metformin. However, metformin has little impact on the prevention of hepatocellular carcinoma in patients with nondiabetic liver disease. Researchers from the University of Ferrara in Italy used carbon tetrachloride (CCl4) to treat transgenic mice overexpressing microRNA-221 (miR-221) to establish a liver cancer mouse model with a cirrhosis background. ${ }^{72}$ The mice were administered metformin at $250 \mathrm{mg} / \mathrm{kg} / \mathrm{d}$ (equivalent to the standard $1500 \mathrm{mg}$ dose for diabetic patients). The results demonstrated that metformin improved the liver function of mice, inhibited the activation of hepatic stellate cells, reduced liver fibrosis, reduced lipid accumulation in hepatocytes, delayed the progression of decompensated cirrhosis, and preventedCCl4-induced development of primary liver cancer in transgenic mice. This study revealed the rationale for the use of metformin in patients with liver cirrhosis, regardless of diabetes status. ${ }^{72}$

There is little controversy regarding the protective effect of metformin on liver cancer, but most clinical studies have been conducted in diabetic patients and few on liver cancer in nondiabetic patients. Therefore, the routine use of metformin in nondiabetic patients with liver cancer is not recommended, and additional clinical studies are needed in nondiabetic patients with liver cancer.

\section{Other Possible Cancers}

In addition to common malignant tumors, metformin has protective effects on other tumors, such as pancreatic cancer, ${ }^{73}$ bladder cancer, ${ }^{74}$ biliary cancer, ${ }^{75}$ renal cancer ${ }^{76}$ and ovarian cancer. ${ }^{77}$ In 2014, the researchers extracted 65,754 age- and sex-matched patients without diabetes and without a previous cancer diagnosis from the database and compared the cancer risk of subjects without diabetes, those with T2DM but without hypoglycemic drugs, those only using metformin, those using hypoglycemic drugs other than metformin, and those using metformin in combination with other hypoglycemic drugs. The results indicated that the extent to which metformin reduced the risk of cancer and prolonged the duration of cancer in patients with T2DM depended on the dose of metformin regardless of whether it was used alone or in combination with other hypoglycemic agents. ${ }^{78}$ In 2018 , a retrospective cohort study using the Taiwan National Health Insurance database revealed that metformin use in women with T2DM reduced the overall risk of endometrial cancer, and there was a dose-response relationship. ${ }^{79} \mathrm{D}$. Y. Leeet al extracted data on Koreans newly diagnosed with diabetes and selected age- and sex-matched controls provided by the National Health Insurance Company for retrospective cohort analysis. Consistent with previous studies, metformin reduced the risk of pancreatic cancer. ${ }^{80}$

In summary, most clinical studies have confirmed that metformin can inhibit the occurrence and development of tumors. However, Srivastava SPet alproposed that these studies potentially exaggerate the tumor-related benefits of metformin. ${ }^{81}$ In 2012, a systematic review and collaborative meta-analysis of randomized clinical trials did not support the hypothesis that metformin had a significant beneficial effect on cancer prognosis. ${ }^{82}$ Seven years later, Oh TK and Song IA conducted a nationwide sample cohort study to analyze the relationship of metformin use and cancer in diabetes patients. ${ }^{83}$ The authors found a lack of an association between metformin treatment and the risk of cancer among diabetic patients, even in the high daily dosage groups ( $>1 \mathrm{~g} /$ day) ${ }^{83}$ However, there might be some confounders or time bias in this study. Thus, further prospective, large population-based cohort studies are needed to confirm these findings.

\section{The Possible Antitumor Mechanism of Metformin}

As mentioned above, most studies indicate that metformin has antitumor effects, but its mechanism has not been fully elucidated. Metformin is thought to have direct and indirect antitumor mechanisms.

\section{Indirect Mechanisms (Figure I) Increased Glucose and Lipid Metabolism}

Hyperglycemia and diabetes increase the risk of cancer. Hyperglycemia can directly or indirectly promote the proliferation, migration, invasion and immune escape of cancer cells. In particular, high glucose can enhance Wnt/ $\beta$-catenin signaling in cancer cells, thus promoting proliferation and growth and inhibiting aging. ${ }^{84}$ Patients with T2DM also have high levels of insulin and insulin-like growth factor 1 (IGF-1). Insulin is the main regulator of cell metabolism and is also a growth factor. Insulin and IGF-1 can promote the occurrence of tumors by stimulating the proliferation of epithelial cells. ${ }^{85,86}$ Metformin can reduce blood glucose levels, improve insulin resistance, and reduce IGF-1 levels by inhibiting glycogen decomposition and hepatic gluconeogenesis, promoting the utilization of glucose in peripheral 


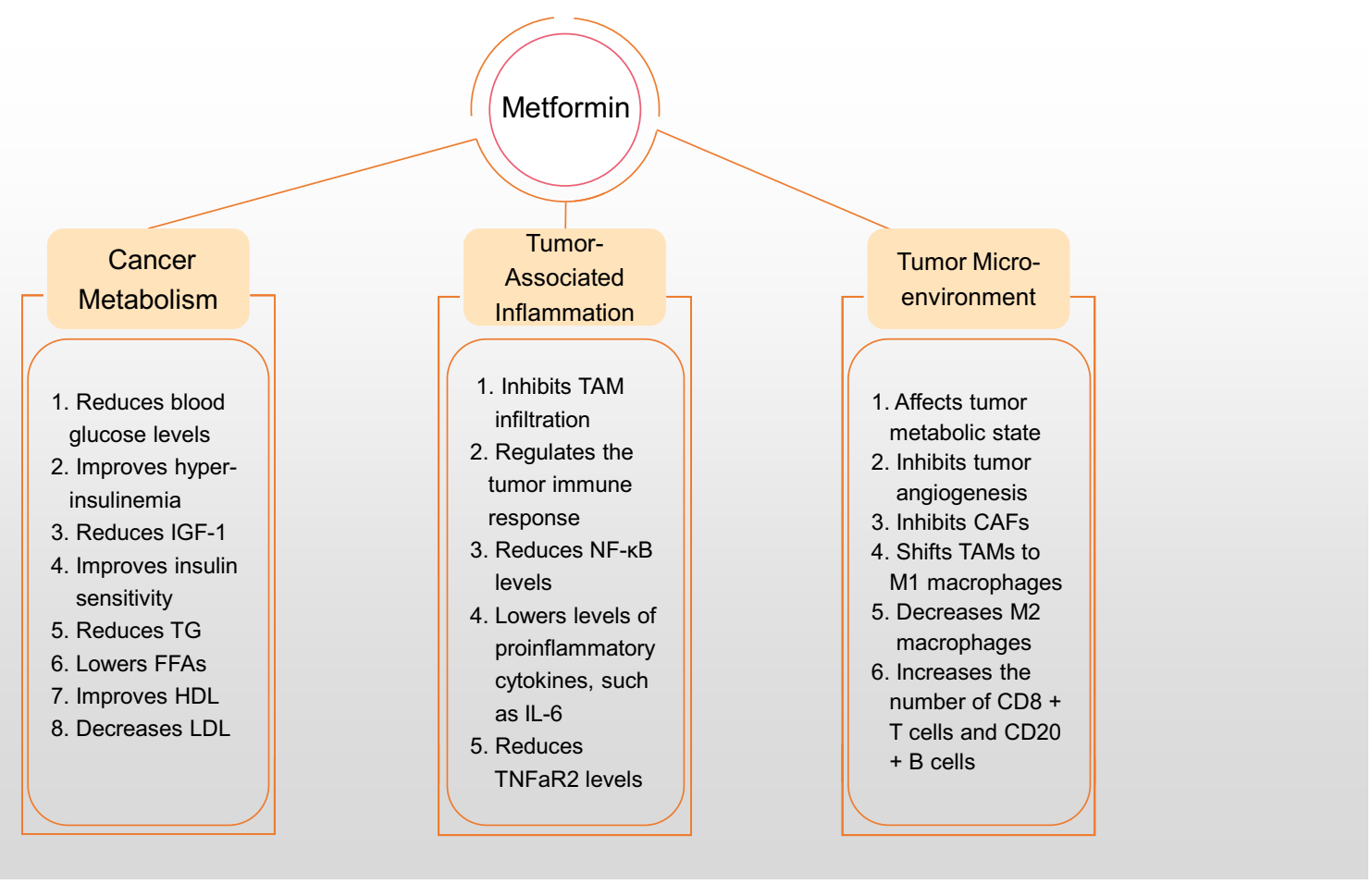

Figure I The indirect anticancer effects of metformin include improving glucose and lipid metabolism, inhibiting tumor-associated inflammation and regulating the tumor microenvironment.

Abbreviations: IGF-I, insulin-like growth factor I; TG, triglyceride; FFA, free fatty acid; HDL-C, high-density lipoprotein cholesterol; LDL-C, low-density lipoprotein cholesterol; TAM, tumor-associated macrophage; NF-KB, nuclear factor kappa B; IL-6, interleukin 6; TNFaR2, TNF- $\alpha$ receptor II; CAFs, tumor-associated fibroblasts.

tissues, increasing the number and affinity of insulin receptors, and improving the activity of tyrosine kinase in muscle and adipose tissues to reduce the risk of tumor occurrence and delay the progression of tumors. ${ }^{87,88}$

It is generally believed that lipid metabolism disorders are associated with nonalcoholic fatty liver disease, atherosclerotic cardio-cerebrovascular disease, obesity and diabetes mellitus.In recent years, an increasing number of studies have shown that dyslipidemia is related to the occurrence and development of tumors (Figure 2). Serum total cholesterol levels in patients with malignant tumors are abnormal to varying degrees, and dyslipidemia can lead to the occurrence of tumors through oxidative stress, insulin resistance, inflammatory pathways and other pathways. ${ }^{89-91}$ Abnormal lipid metabolism is related to the transmission and development of various tumors, such as breast cancer, liver cancer, lung cancer and stomach cancer. For example, 27-hydroxycholesterol, a cholesterol metabolite with estrogen function, can bind to the estrogen receptor of breast cancer cells and promote the reproduction of estrogen receptor-positive breast cancer cells. ${ }^{92}$ The secretion of leptin increases and the production of adiponectin decreases with increasing blood lipid levels. Leptin inhibits the apoptosis of breast cancer cells through the leptin-phosphatidylinositol-3-kinaseprotein kinase B-Bcl-2 axis and directly stimulates the expression of vascular endothelial cell growth factor in breast cancer, thereby promoting the proliferation of tumor cells and the generation of new microvessels. ${ }^{93}$ Metformin can selectively increase the uptake of triglycerides by very low density lipoprotein (VLDL) and the oxidation of fatty acids in brown adipose tissue to reduce the content of triglycerides in plasma to promote the circulation of blood lipid metabolism (Figure 2). ${ }^{94}$ Metformin also activates AMPK and inhibits $\alpha$ dicarbonyl-mediated modification of apolipoprotein residues, thereby improving high-density lipoprotein(HDL) dysfunction and reducing low-density lipoprotein(LDL) modification, improving cholesterol transport, and reducing lipid storage in tissues, thus reducing the occurrence and development of tumors. ${ }^{95-97}$ In addition, metformin restricts calorie intake, which reduces lipid uptake by cancer cells from plasma and tissue fluid, increases toxic saturated fatty acid levels by inhibiting the activity of stearoyl coenzyme A desaturase, and inhibits the progression of pancreatic ductal adenocarcinoma. ${ }^{98}$ 


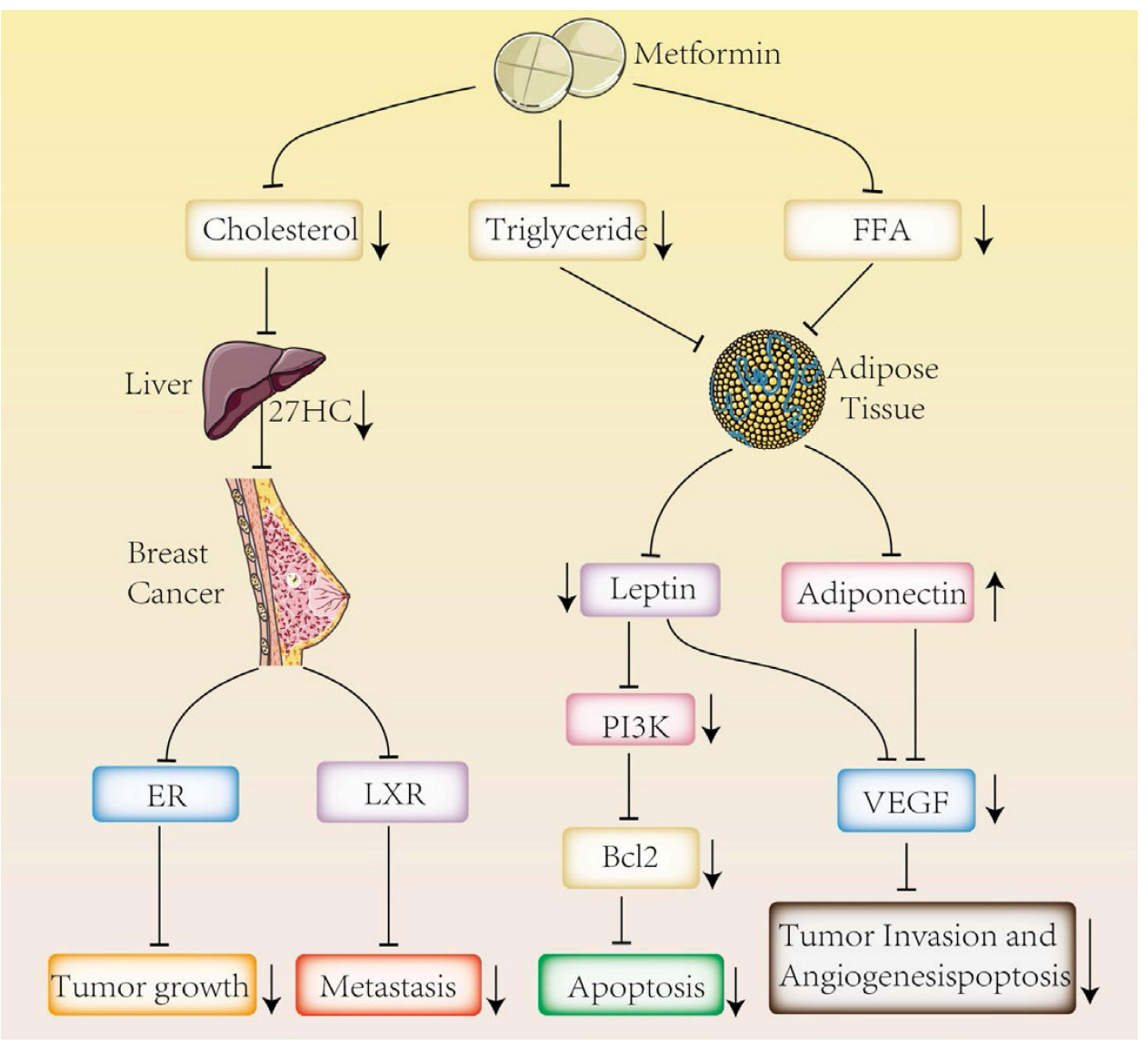

$\longrightarrow$ represents inhibition

Figure 2 Metformin inhibits cancer by suppressing lipid metabolism.

Abbreviations: FFA, free fatty acid; 27HC, 27-hydroxycholesterol; ER, estrogen receptor; LXR, liver X receptor; PI3K, phosphatidylinositol-3-kinase-protein kinase B; Bcl2, VEGF, vascular endothelial growth factor.

\section{Inhibition of Tumor-Associated Inflammation}

Chronic inflammation is associated with various steps of tumorigenesis and development, including cell transformation, survival, proliferation, invasion, angiogenesis and metastasis. ${ }^{99}$ Cancer itself or inflammation caused by cancer can be triggered by mutations involved in cancer initiation and contributes to malignant progression by recruiting and activating inflammatory cells. Tumorassociated macrophages and the inflammation-activated transcription factor nuclear factor kappa B (NF-кB) signaling pathway stimulate the growth and proliferation of tumor cells and promote tumor invasion and metastasis. ${ }^{100,101}$ Metformin inhibits tumor-related inflammation to reduce the risk of tumor occurrence and delay tumor progression. The effects of metformin on tumorassociated inflammation at the onset of prostate cancer after ADT were examined in a transgenic prostate cancer mouse model, an in vitro macrophage migration test and in prostate cancer samples. The results indicated that metformin inhibited tumor-associated macrophage (TAM) infiltration by inhibiting the COX2/PGE2 axis, especially androgen deprivation induced by castration treatment of macrophage infiltration, thereby inhibiting the progression of prostate cancer. ${ }^{102}$ De Oliveira S used optically transparent zebrafish to observe the effects of metformin on the early immune response of the liver and the progression of primary liver cancer. ${ }^{103}$ The results suggested that metformin treatment changes the macrophage polarization of NAFLD/NAFLD-related liver cancer induced by a highfat diet, restores the reduced liver $T$ cell density induced by a high-fat diet, and thus regulates the tumor immune response, which may have a role in tumor monitoring. ${ }^{103}$ An observational study reported that metformin treatment for 12 weeks can reduce serum sTNFaR2 concentrations in patients with breast cancer and rectal cancer and that TNF$\alpha$ promotes tumor growth by activating $\mathrm{NF}-\kappa \mathrm{B}$ through 
sTNFaR2. ${ }^{104,105}$ In addition, metformin blocks the activity of $\mathrm{NF}-\kappa \mathrm{B}$ to reduce the secretion of proinflammatory cytokines; ${ }^{106}$ metformin also activates the immune response of cancer cells, and these inflammatory processes play an important role in tumor progression. ${ }^{86}$ Metformin specifically reduces the expression of the IL-6 receptor at the transcriptional level through AMPK, mTOR, and miR$34 \mathrm{a}$, inhibits the activation of STAT3 by IL-6, inhibits the STAT signaling pathway, downregulates Bcl-2 and cyclin $\mathrm{D} 1$, and upregulates the activity of $\mathrm{P} 21$ protein, thus inhibiting the proliferation and inducing the apoptosis of multiple myeloma cells. ${ }^{107}$

\section{Regulation of the Tumor Microenvironment}

Cancer is a complex system in which cancer cells coexist and interact with several different types of nonmalignant cells. Therefore, anticancer drugs affect not only cancer cells but also tumor microenvironment cells. In recent years, an accumulating body of research has indicated that the tumor microenvironment has a significant effect on tumor cells and tumor metabolism. Tumor cell self-metabolism, interaction between immune cells and tumor cells, tumor location and heterogeneity, individual overall metabolic status and diet all have certain effects on the tumor cell microenvironment. ${ }^{98}$ Studies have shown that metformin inhibits tumor growth, proliferation and metastasis by affecting the tumor-associated microenvironment, such as the tumor metabolic state, tumor angiogenesis, cancer-associated fibroblasts (CAFs), and tumor-associated immune cells. ${ }^{108}$

The main feature of tumor metabolic reprogramming is abnormal redox metabolism (glucose metabolism is dominated by aerobic metabolism). Metformin can inhibit oxidative phosphorylation and reduce ATP levels under low-glucose conditions, which can promote tumor cell death. ${ }^{109}$ The alteration of lipid metabolism is also an important aspect of tumor metabolic reprogramming. High fatty acid turnover in tumor cells is induced to meet the energy and synthesis requirements of tumor growth. ${ }^{110}$ Fatty acid synthase is a metabolic oncogene that supports the growth and survival of tumor cells and is highly expressed in many cancers. ${ }^{111}$ Studies have found that metformin has the ability to inhibit adipogenesis and adipocyte-mediated ovarian tumor proliferation and metastasis, and it is recommended as a treatment option for early ovarian cancer, not only because of its tumor suppressive potential but also because of its role in changing the cancer microenvironment. ${ }^{112,113}$

It was also found that metformin could inhibit angiogenesis signaling. Metformin reduces the stability of hypoxia inducible factor-1 $\alpha$ (HIF-1 $\alpha)$ in tumor cells and the expression of HIF-1-targeted genes, including vascular endothelial growth factor-A (VEGF-A), resulting in slow tumor growth, smaller tumor vessels and lower microvessel density. ${ }^{114-116}$ CAFs facilitate tumor progression by providing angiogenic factors and nutrients, serving as extracellular matrix proteins of scaffolds, and providing mechanical signals for tumor cell invasion. ${ }^{117}$ Metformin inhibits cancer progression by directly preventing NF- $\kappa \mathrm{B}$ proinflammatory signaling from CAFs. ${ }^{118}$ TAMs include proinflammatory and antitumor M1 macrophages and M2 macrophages that promote tumor healing. Studies have suggested that metformin therapy is associated with the suppression of macrophage-mediated inflammatory signals. It has been suggested that metforminmediated increases in the intracellular oxygen concentration can help to reduce hypoxia in some tumors, leading to the shift of TAMs to M1 macrophages. ${ }^{119}$ In addition, metformin can downregulate NF- $\mathrm{BB}$ by activating AMPK or other unknown factors, modifying inflammatory components, and ultimately promoting the M1 phenotype. ${ }^{120}$ Some studies have indicated that metformin is related to the reduction of TAMs in tumor tissues and the transformation of TAMs to M1. ${ }^{121}$ In addition, metformin is associated with a decrease in M2 macrophages because the downregulation of arg1 was observed after metformin treatment of breast cancer macrophages. ${ }^{102}$ Cancer cells decrease the cytotoxicity of lymphocytes through a variety of mechanisms, the most famous of which is the overexpression of programmed death ligand 1 (PD-L1), which leads to the failure of cytotoxic $T$ cells, leading to immunosuppression and cancer cell survival. ${ }^{122}$ Metformin treatment can directly increase the antitumor toxicity of lymphocytes, relieve cancer immunosuppression by reducing the expression of PD-L1 on the cancer cell membrane or suppress the function of bone marrow-derived suppressor cells, thus increasing the antitumor toxicity of lymphocytes. ${ }^{123,124}$ Recently, reprogramming of the immune microenvironment has attracted attention in the role of tumors. In an esophageal squamous cell carcinoma (ESCC) mouse model of tumor immune microenvironment reprogramming, researchers analyzed ESCC samples from mice before and after metformin ( $250 \mathrm{mg} /$ day) treatment and those from mice treated with low-dose metformin $(50 \mathrm{mg} / \mathrm{kg}$ / day) for 1 week (short term) or 12 weeks (long term); the results showed that metformin treatment reprogrammed the tumor immune microenvironment to an "invasive inflammatory" state and increased the number of infiltrating CD8+ T lymphocytes and CD20+ B lymphocytes. In addition, the number of tumor suppressor (CD11c+) macrophages 
increased, and the number of tumor-promoting (CD163+) macrophages decreased. In vitro, metformin enhanced the macrophage-mediated phagocytosis of ESCC cells; in both humans and mice, metformin triggered AMPK activation and STAT3 inactivation and altered the secretion of cytokines (such as TNF $\alpha$, IFN $\gamma$ and IL-10) from immune cells. These results indicate that low-dose metformin reprograms the tumor immune microenvironment to the activated state, so metformin may be an appropriate immune response regulator and is worthy of further study. ${ }^{102}$

Recent studies have indicated that AMPK can control the differentiation of gastric epithelial progenitor cells. Metformin activates AMPK and KLF4, reduces the proliferation of mouse epithelial progenitor cells, increases acid-secreting gastric parietal cells, and activates AMPK and PGC-1a to induce the maturation of gastric parietal cells, thereby increasing gastric acid secretion and indirectly reducing the risk of gastric cancer. ${ }^{65}$

\section{Direct Mechanisms (Figure 3)}

The direct anticancer effect of metformin is related to two mechanisms: adenosine monophosphate (AMP)-dependent and AMP-independent activation of the protein kinase (AMPK) pathway. ${ }^{125}$ The most significant mechanism of metformin is the activation of AMPK. ${ }^{125}$ AMPK is a highly conserved cell energy state sensor. Under metabolic stress conditions, such as hypoxia and glucose deficiency, the ratio of AMP/ATP increases, leading to AMPK activation. mTOR signaling is a major regulator of cell growth and proliferation. AMPK can inhibit cell growth and biosynthesis by inhibiting the mTORC1pathway. ${ }^{126}$ $\mathrm{C}$-myc is a major regulator of cancer cell metabolism and can affect glycolysis and glutamine catabolism in cancer cells in different tissues. miRNA regulation is the basis of metformin's anticancer mechanism. Metformin activates the AMPK-DICER-miRNA axis or directly upregulates the DICER-miRNA axis to further decrease the

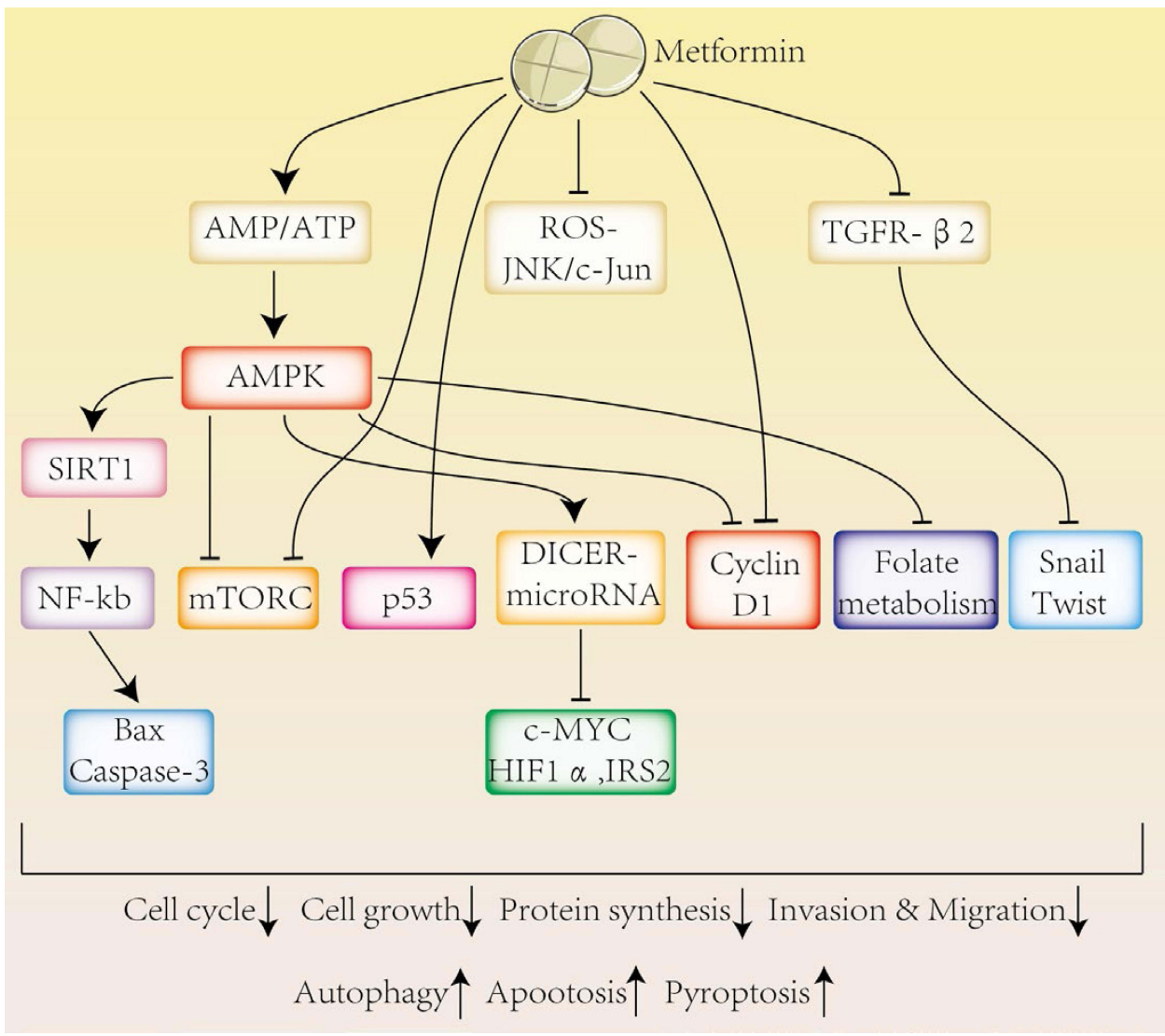

\section{represents inhibition represents facilitation}

Figure 3 The direct anticancer effects of metformin. Metformin inhibits cancer by activating AMPK and p53 and inhibitingmTORC, cyclin DI, ROS-JNK/c-Jun and TGFR- $\beta 2$. 
levels of c-MYC, HIF-1 $\alpha$ and IRS2, eventually disrupting the metabolism of tumor cells and inhibiting the occurrence and development of tumors. ${ }^{127}$ Previous studies have suggested that compared with that in human plasma, the folic acid concentration in standard cell culture medium from cancer cell lines is relatively high. Metformin can be used as an anti-folic acid chemotherapy drug to inhibit tumor proliferation by activating the ATM/AMPK tumor inhibition signaling pathway, changing the carbon flow of the folate-related single carbon metabolic pathway, and disrupting folate metabolism. ${ }^{128}$ P53 has many biological functions, including regulating cell growth, survival, development, senescence and senescence. ${ }^{129}$ AMPK phosphorylation induces cell cycle arrest by direct phosphorylation of p53. ${ }^{130}$ Studies have suggested that metformin inhibits the proliferation and induces the apoptosis of cervical cancer cells by activating AMPK or other signaling pathways, downregulating cyclin D1 and upregulating p53. ${ }^{130}$

Cell apoptosis, autophagy and pyroptosis are important mechanisms of programmed cell death. Many studies have suggested that apoptosis and autophagy play a major role in inflammation, immune responses and cancer progression. ${ }^{131,132}$ Metformin inhibits the proliferation of myeloma cells by activating AMPK to restrain the mTORC1 and mTORC2 pathways, further inducing autophagy and arresting the cell cycle. ${ }^{133}$ Liu $\mathrm{S}$ and others have indicated that metformin inhibits the proliferation, invasion and metastasis of gastric cancer cells by inducing Beclin 1-dependent autophagy through the AMPK mTOR signaling pathway. ${ }^{134}$ Pyroptosis is a newly discovered proinflammatory programmed cell death pathway that is characterized by the continuous expansion of cells until membrane rupture, leading to the release of cell contents and the activation of an intense inflammatory response. Recently, Zheng $\mathrm{Z}$ showed that metformin activates the AMPK/SIRT1/NF- $\kappa$ B signaling pathway, promotes the accumulation of Bax and the release of cytochrome $\mathrm{C}$, and ultimately triggers the activation of caspase-3 and the cleavage of GSDME in cancer cells, leading to pyroptosis. In addition, these authors found that metformin promotes mitochondrial dysfunction that induces the AMPK/SIRT1 pathway, leading to pyroptosis. ${ }^{135}$ Induced cell pyroptosis is considered a new therapeutic protocol for the treatment of various cancers. Leucine-rich protein-1 (PELP1), a scaffolding oncogene, is upregulated in advanced ESCC and is highly related to cancer progression and patient prognosis. Wang $\mathrm{L}$ et al found that metformin treatment resulted in gasdermin D (GSDMD)-mediated pyroptosis, which was abrogated by forced expression of PELP1. The authors noted that metformin induced pyroptosisinESCC cells by targeting the miR-497/PELP1 axis.Their results showed that metformin and any other pyroptosis-inducing reagents have tremendous potential in treating chemotherapy- and radiation-resistant ESCC. ${ }^{136}$ Induced cell apoptosis is considered a new therapeutic protocol for the treatment of various cancers.

Metformin also inhibits the development and progression of tumors independent of the AMPK signaling pathway. Metformin induces apoptosis and autophagy in ESCC cells by inactivating STAT3 and restraining Bcl- $2^{137}$ and induces apoptotic pathways by activating caspase- 3 in human adrenocortical and pancreatic cancer cells. ${ }^{138,139}$ In addition, metformin induces mitochondrial apoptosis in cancer cells by increasing the protein levels of Bax and cleaved caspase-3 in ovarian cancer cells. ${ }^{140}$ Metformin also inhibits the growth and invasion of hepatoma cells through the $\mathrm{PI} 3 \mathrm{~K} / \mathrm{Akt} / \mathrm{mTOR}$ pathway and induces the apoptosis and autophagy of hepatoma cells. $^{141}$ Recent studies have suggested that metformin induces cell cycle arrest and programmed cell death, including apoptosis and autophagy, in human osteosarcoma cells through the ros-jnk/c-Jun cascade. ${ }^{142}$ In addition, metformin can further promote the apoptosis of primary breast cancer cells by downregulating cyclin D1 and upregulating p53 independent of the AMPK signaling pathway. ${ }^{143}$ Ji-Hye Park et al studied the effect of metformin on drug-resistant colorectal cancer. The results suggested that metformin improves the sensitivity of these cell lines to chemotherapeutic drugs by inhibiting the proliferation of rectal cancer cells, inhibiting their colony formation ability and increasing their apoptosis. In addition, metformin and diphenylguanidine inhibit the expression of snail and twist mediated by transforming growth factor beta receptor 2 (TGFR- $\beta 2$ ) to affect the migration and invasion of rectal cancer cells. ${ }^{144}$

\section{Conclusion and Prospective}

Metformin is the first-choice antidiabetic drug for T2DM; its molecular target is AMPK. AMPK is involved in many metabolic processes and plays an important role in many contexts. Metformin not only lowers blood glucose levels and ameliorates insulin resistance but also inhibits lipolysis and reduces cardiovascular complications in patients with T2DM. In recent years, metformin was declared to have antiaging, hair growth-promoting, cognitive impairment-reversing, and antitumor effects. 
At present, most clinical studies have proven that metformin treatment can reduce the risk of cancer and improve the survival of cancer patients. However, the benefits of metformin for some cancer patients are not clear. Metformin may be related to the rate of progression of these cancers, their special mechanisms and their therapeutic effect. The results are also related to the time window deviation of some clinical studies, the inclusion of population, study design and the failure to consider the economic conditions of patients. In addition, metformin is taken orally. Due to its polarity, metformin needs to enter cells through membrane transporters. Organic cation transporters (OCTs) are important transporters for metformin to enter cells, and tumor cells can express OCT1. However, different tumor cells have different expression levels of OCT1, and a decreased expression of OCT1 in tumor cells will reduce the uptake of metformin, thus affecting the effective concentration of metformin in cells and the exertion of its effects, which may also lead to the difference in the benefits of metformin in different tumors. Currently, the protective effects of metformin on many types of cancer, such as lung cancer, gastric cancer, colorectal cancer and liver cancer, are less controversial, and metformin may be considered adjuvant therapy in these cancer patients. However, the effects of metformin on breast cancer and prostate cancer are still debated, and it is not recommended to be used in cancer patients without diabetes. Additional prospective studies are needed to verify the effect of metformin on different types of cancer. In addition, further evaluation of OCT1expression in different tumor cells is conducive to better understanding the antitumor effect of metformin.In addition, most studies on tumors with metformin were based on T2DM, with few related studies on cancer without DM. We hope that an increasing number of indepth studies will be conducted to further explore the relationship between metformin and cancer and provide strong evidence for the clinical application of metformin in cancer patients.

Most basic studies have indicated that metformin inhibits the growth of tumor cells and promotes cell apoptosis, while clinical studies have yielded inconsistent results. This disparity can be explained by the difference in metformin concentration between basic research and clinical research. The maximum recommended dose of metformin for T2DM is $2500 \mathrm{mg} / \mathrm{d}$, and the dose used in cell and mouse studies is far higher than that in human blood. Metformin directly activates the AMPK signaling pathway to inhibit the occurrence and development of tumors, inhibits the production of ROS via mitochondrial respiratory chain complex I, induces the activation of mTORC1, inhibits cyclin D1 and then inhibits the growth of tumors. In addition, metformin indirectly inhibits tumor growth, proliferation, invasion and metastasis by decreasing blood glucose levels, attenuating insulin resistance, reducing inflammation and improving the tumor microenvironment. Glycolysis plays a critical role in the energy metabolism of tumor cells and metformin has a certain inhibitory effect on glycolysis.At present, studies on the mechanism of metformin's antitumor effects are becoming increasingly in-depth, but some controversies remain. Additional research is needed to uncover the mystery of metformin to allow for its better application in the clinic and to achieve better inhibition of tumor growth.

\section{Acknowledgments}

This work was supported by grants from the National Natural Science Foundation of China (81370885), 2019 Merck Diabetes Research Fund (g-x-2019-056), Chongqing Science and Technology Bureau and Health Commission Joint TCM technology innovation and application development project (2020zy013540), Joint Medical Research Project of Chongqing Science and Technology Bureau and Health Commission (2021msxm311), and Research Institute Performance Incentive and Guidance Project of Chongqing Science and Technology Bureau (cstc2019jxj1130006).

\section{Disclosure}

The authors declare no conflicts of interest.

\section{References}

1. World Health Organization. Global Health Observatory. Geneva: World Health Organization; 2018. Available from: who.int/gho/data base/en/. Accessed June 21, 2018.

2. Sung H, Ferlay J, Siegel RL, et al. Global cancer statistics 2020: GLOBOCAN estimates of incidence and mortality worldwide for 36 cancers in 185 countries. CA Cancer J Clin. 2021;71(3):209-249. doi: $10.3322 /$ caac. 21660

3. Abudawood M. Diabetes and cancer: a comprehensive review. $J$ Res Med Sci. 2019;24:94. doi:10.4103/jrms.JRMS_242_19

4. Onitilo AA, Engel JM, Glurich I, et al. Diabetes and cancer I: risk, survival, and implications for screening. Cancer Causes Control. 2012;23(6):967-981. doi:10.1007/s10552-012-9972-3

5. Simon D, Balkau B. Diabetes mellitus, hyperglycaemia and cancer. Diabetes Metab. 2010;36(3):182-191. doi:10.1016/j. diabet.2010.04.001

6. Wolf I, Sadetzki S, Catane R, et al. Diabetes mellitus and breast cancer. Lancet Oncol. 2005;6(2):103-111. doi:10.1016/S14702045(05)01736-5 
7. Day EA, Ford RJ, Smith BK, et al. Metformin-induced increases in GDF15 are important for suppressing appetite and promoting weight loss. Nat Metab. 2019;1(12):1202-1208. doi:10.1038/ s42255-019-0146-4

8. Bharath LP, Agrawal M, McCambridge G, et al. Metformin enhances autophagy and normalizes mitochondrial function to alleviate aging-associated inflammation. Cell Metab. 2020;32 (1):44-55.e6. doi:10.1016/j.cmet.2020.04.015

9. Samaras K, Makkar S, Crawford JD, et al. Metformin use is associated with slowed cognitive decline and reduced incident dementia in older adults with type 2 diabetes: the sydney memory and ageing study. Diabetes Care. 2020;43(11):2691-2701. doi:10.2337/dc20-0892

10. Chan AT. Metformin for cancer prevention: a reason for optimism. Lancet Oncol. 2016;17(4):407-409. doi:10.1016/ S1470-2045(16)00006-1

11. Wheaton WW, Weinberg SE, Hamanaka RB, et al. Metformin inhibits mitochondrial complex I of cancer cells to reduce tumorigenesis. Elife. 2014;3:e02242. doi:10.7554/eLife.02242

12. Evans JM, Donnelly LA, Emslie-Smith AM, et al. Metformin and reduced risk of cancer in diabetic patients. BMJ. 2005;330 (7503):1304-1305. doi:10.1136/bmj.38415.708634.F7

13. Samuel SM, Varghese E, Varghese S, et al. Challenges and perspectives in the treatment of diabetes associated breast cancer. Cancer Treat Rev. 2018;70:98-111. doi:10.1016/j.ctrv.2018.08.004

14. Col NF, Ochs L, Springmann V, et al. Metformin and breast cancer risk: a meta-analysis and critical literature review. Breast Cancer Res Treat. 2012;135(3):639-646. doi:10.1007/s10549012-2170-x

15. Rennert G, Rennert HS, Gronich N, et al. Use of metformin and risk of breast and colorectal cancer. Diabetes Res Clin Pract. 2020;165:108232. doi:10.1016/j.diabres.2020.108232

16. Patterson RE, Marinac CR, Sears DD, et al. The effects of metformin and weight loss on biomarkers associated with breast cancer outcomes. J Natl Cancer Inst. 2018;110(11):1239-1247. doi:10.1093/jnci/djy040

17. Chen L, Chubak J, Boudreau DM, et al. Diabetes Treatments and risks of adverse breast cancer outcomes among early-stage breast cancer patients: a SEER-medicare analysis. Cancer Res. 2017;77 (21):6033-6041. doi:10.1158/0008-5472.CAN-17-0687

18. Wang JC, Li GY, Wang B, et al. Metformin inhibits metastatic breast cancer progression and improves chemosensitivity by inducing vessel normalization via PDGF-B downregulation. J Exp Clin Cancer Res. 2019;38(1):235. doi:10.1186/s13046-0191211-2

19. Pollak MN. Investigating metformin for cancer prevention and treatment: the end of the beginning. Cancer Discov. 2012;2 (9):778-790. doi:10.1158/2159-8290.CD-12-0263

20. Cazzaniga M, Bonanni B, Guerrieri-Gonzaga A, et al. Is it time to test metformin in breast cancer clinical trials? Cancer Epidemiol Biomarkers Prev. 2009;18(3):701-705. doi:10.1158/1055-9965. EPI-08-0871

21. Goodwin PJ, Ligibel JA, Stambolic V. Metformin in breast cancer: time for action. J Clin Oncol. 2009;27(20):3271-3273. doi:10.1200/JCO.2009.22.1630

22. Goodwin PJ, Stambolic V, Lemieux J, et al. Evaluation of metformin in early breast cancer: a modification of the traditional paradigm for clinical testing of anti-cancer agents. Breast Cancer Res Treat. 2011;126(1):215-220. doi:10.1007/s10549-010-1224-1

23. Bonanni B, Puntoni M, Cazzaniga M, et al. Dual Effect of metformin on breast cancer proliferation in a randomized presurgical trial. J Clin Oncol. 2012;30(21):2593-2600. doi:10.1200/ JCO.2011.39.3769

24. Yin L, Duan JJ, Bian XW, et al. Triple-negative breast cancer molecular subtyping and treatment progress. Breast Cancer Res. 2020;22(1):61. doi:10.1186/s13058-020-01296-5
25. Wahdan-Alaswad R, Fan Z, Edgerton SM, et al. Glucose promotes breast cancer aggression and reduces metformin efficacy. Cell Cycle. 2013;12(24):3759-3769. doi:10.4161/cc.26641

26. Wahdan-Alaswad RS, Cochrane DR, Spoelstra NS, et al. Metformin-induced killing of triple-negative breast cancer cells is mediated by reduction in fatty acid synthase via miRNA-193b. Horm Cancer. 2014;5(6):374-389. doi:10.1007/s12672-014-0188-8

27. Wahdan-Alaswad RS, Harrell JC, Fan Z, et al. Metformin attenuates transforming growth factor beta (TGF- $\beta$ ) mediated oncogenesis in mesenchymal stem-like/ claudin-low triple negative breast cancer. Cell Cycle. 2016;15(8):1046-1059. doi:10.1080/ 15384101

28. Wahdan-Alaswad RS, Salem HS, Edgerton SM, et al. Metformin targets cholesterol biosynthesis pathway, GM1 lipid raft stabilization, EGFR signaling and proliferation in triple. Negative Breast Cancers. 2018;9(3):555765. doi:10.19080/ CTOIJ.2018.09.555765

29. Liu B, Fan Z, Edgerton SM, et al. Potent anti-proliferative effects of metformin on trastuzumab- resistant breast cancer cells via inhibition of ErbB2/IGF-1 receptor interactions. Cell Cycle. 2011;10(17):2959-2966. doi:10.4161/cc.10.17.16359

30. Hen H, Cook LS, Tang MC, et al. Relationship between diabetes and diabetes medications and risk of different molecular subtypes of breast cancer. Cancer Epidemiol Biomarkers Prev. 2019;28 (11):1802-1808. doi:10.1158/1055-9965

31. Dhillon SS, Groman A, Meagher A, et al. Metformin and Not diabetes influences the survival of resected early stage NSCLC Patients. J Cancer Sci Ther. 2014;6(7):217-222. doi:10.4172/ 1948-5956.1000275

32. Arrieta O, Varela-Santoyo E, Soto-perez-de-celis E, et al. Metformin use and its effect on survival in diabetic patients with advanced non-small cell lung cancer. BMC Cancer. 2016;16:633. doi:10.1186/s12885-016-2658-6

33. Chen H, Yao W, Chu Q, et al. Synergistic effects of metformin in combination with EGFR-TKI in the treatment of patients with advanced non-small cell lung cancer and type 2 diabetes. Cancer Lett. 2015;369(1):97-102. doi:10.1016/j.canlet.2015.08.024

34. $\mathrm{Xu} \mathrm{T}$, $\mathrm{Li} \mathrm{D}, \mathrm{He} \mathrm{Y}$, et al. Prognostic value of metformin for non-small cell lung cancer patients with diabetes. World J Surg Oncol. 2018;16(1):60. doi:10.1186/s12957-018-1362-1

35. Xu T, Liang G, Yang L, et al. Prognosis of small cell lung cancer patients with diabetes treated with metformin. Clin Transl Oncol. 2015;17(10):819-824. doi:10.1007/s12094-015-1311-1

36. Kong F, Gao F, Liu H, et al. Metformin use improves the survival of diabetic combined small-cell lung cancer patients. Tumour Biol. 2015;36(10):8101-8106. doi:10.1007/s13277-015-3549-1

37. Kang J, Jeong SM, Shin DW, et al. Associations of aspirin, statins, and metformin with lung cancer risk and related mortality: time-dependent analysis of population-based nationally representative data. J Thorac Oncol. 2021;16(1):76-88. doi:10.1016/j. jtho.2020.08.021

38. Zeng S, Gan HX, Xu JX, et al. Metformin improves survival in lung cancer patients with type 2 diabetes mellitus: a meta-analysis. Med Clin (Barc). 2019;152(8):291-297. doi:10.1016/j.medcli.2018.06.026

39. Brancher S, Støer NC, Weiderpass E, et al. Metformin use and lung cancer survival: a population-based study in Norway. Br J Cancer. 2021;124(5):1018-1025. doi:10.1038/s41416-020-01186-9

40. Zhou X, Liu S, Lin X, et al. Metformin Inhibit lung cancer cell growth and invasion in vitro as well as tumor formation in vivo partially by activating PP2A. Med Sci Monit. 2019;25:836-846. doi:10.12659/MSM.912059

41. Guraya SY. Association of type 2 diabetes mellitus and the risk of colorectal cancer: a meta-analysis and systematic review. World $J$ Gastroenterol. 2015;21(19):6026-6031. doi:10.3748/wjg.v21. i19.6026 
42. Larsson SC, Orsini N, Wolk A. Diabetes mellitus and risk of colorectal cancer: a meta-analysis. J Natl Cancer Inst. 2005;97 (22):1679-1687. doi:10.1093/jnci/dji375

43. Yang YX, Hennessy S, Lewis JD. Insulin therapy and colorectal cancer risk among type 2 diabetes mellitus patients. Gastroenterology. 2004;127(4):1044-1050. doi:10.1053/j. gastro.2004.07.011

44. Bradley MC, Ferrara A, Achacoso N, et al. A cohort study of metformin and colorectal cancer risk among patients with diabetes mellitus. Cancer Epidemiol Biomarkers Prev. 2018;27 (5):525-530. doi:10.1158/1055-9965

45. Higurashi T, Hosono K, Takahashi H, et al. Metformin for chemoprevention of metachronous colorectal adenoma or polyps in post-polypectomy patients without diabetes: a multicentre double-blind, placebo-controlled, randomised Phase 3 trial. Lancet Oncol. 2016;17(4):475-483. doi:10.1016/S1470-2045(15) 00565-3

46. Fernandes JM, Jandrey EHF, Koyama FC, et al. Metformin as an Alternative radiosensitizing agent to 5-fluorouracil during neoadjuvant treatment for rectal cancer. Dis Colon Rectum. 2020;63 (7):918-926. doi:10.1097/DCR.0000000000001626

47. Xie J, Xia L, Xiang W, et al. Metformin selectively inhibits metastatic colorectal cancer with the KRAS mutation by intracellular accumulation through silencing MATE1. Proc Natl Acad Sci $U \quad S \quad$ A. 2020;117(23):13012-13022. doi: $10.1073 /$ pnas. 1918845117

48. Kasper JS, Giovannucci E. A meta-analysis of diabetes mellitus and the risk of prostate cancer. Cancer Epidemiol Biomarkers Prev. 2006;15(11):2056-2062. doi:10.1158/1055-9965

49. Hankinson SJ, Fam M, Patel NN. A review for clinicians: prostate cancer and the antineoplastic properties of metformin. Urol Oncol. 2017;35(1):21-29. doi:10.1016/j.urolonc.2016.10.009

50. Lee MJ, Jayalath $\mathrm{VH}, \mathrm{Xu} \mathrm{W}$, et al. Association between metformin medication, genetic variation and prostate cancer risk. Prostate Cancer Prostatic Dis. 2021;24(1):96-105. doi:10.1038/ s41391-020-0238-y

51. Margel D, Urbach DR, Lipscombe LL, et al. Metformin use and all-cause and prostate cancer-specific mortality among men with diabetes. J Clin Oncol. 2013;31(25):3069-3075. doi:10.1200/ JCO.2012.46.7043

52. Tseng CH. Metformin significantly reduces incident prostate cancer risk in Taiwanese men with type 2 diabetes mellitus. Eur J Cancer. 2014;50(16):2831-2837. doi:10.1016/j. ejca.2014.08.007

53. Yang B, Damodaran S, Khemees TA, et al. Synthetic lethal metabolic targeting of androgen deprived prostate cancer cells with metformin. Mol Cancer Ther. 2020:2019. doi:10.1158/ 1535-7163

54. Dai C, Heemers H, Sharifi N. Androgen signaling in prostate cancer. Cold Spring Harb Perspect Med. 2017;7(9):a030452. doi:10.1101/cshperspect.a030452

55. Demir U, Koehler A, Schneider R, et al. Metformin anti-tumor effect via disruption of the MID1 translational regulator complex and AR downregulation in prostate cancer cells. BMC Cancer. 2014;14:52. doi:10.1186/1471-2407-14-52

56. Wang Y, Liu G, Tong D, et al. Metformin represses androgen-dependent and androgen-independent prostate cancers by targeting androgen receptor. Prostate. 2015;75(11):1187-1196. doi: $10.1002 /$ pros. 23000

57. Miao ZF, Xu H, Xu YY, et al. Diabetes mellitus and the risk of gastric cancer: a meta-analysis of cohort studies. Oncotarget. 2017;8(27):44881-44892. doi:10.18632/oncotarget.16487

58. Zhou XL, Xue WH, Ding XF, et al. Association between metformin and the risk of gastric cancer in patients with type 2 diabetes mellitus: a meta-analysis of cohort studies. Oncotarget. 2017;8 (33):55622-55631. doi:10.18632/oncotarget.16973
59. Tseng $\mathrm{CH}$. Metformin reduces gastric cancer risk in patients with type 2 diabetes mellitus. Aging. 2016;8(8):1636-1649. doi:10.18632/aging.101019

60. Ruiter R, Visser LE, van Herk-sukel MP, et al. Lower risk of cancer in patients on metformin in comparison with those on sulfonylurea derivatives: results from a large population-based follow-up study. Diabetes Care. 2012;35(1):119-124. doi: $10.2337 / \mathrm{dc} 11-0857$

61. Cheung KS, Chan EW, Wong AYS, et al. Metformin use and gastric cancer risk in diabetic patients after helicobacter pylori eradication. $J$ Natl Cancer Inst. 2019;111(5):484-489. doi:10.1093/jnci/djy144

62. Lee CK, Jung M, Jung I, et al. Cumulative metformin use and its impact on survival in gastric cancer patients after gastrectomy. Ann Surg. 2016;263(1):96-102. doi:10.1097/ SLA.0000000000001086

63. Kim J, Hyun HJ, Choi EA, et al. Metformin use reduced the risk of stomach cancer in diabetic patients in Korea: an analysis of Korean NHIS-HEALS database. Gastric Cancer. 2020;23 (6):1075-1083. doi:10.1007/s10120-020-01085-1

64. Han G, Gong H, Wang Y, et al. AMPK/mTOR-mediated inhibition of survivin partly contributes to metformin-induced apoptosis in human gastric cancer cell. Cancer Biol Ther. 2015;16 (1):77-87. doi:10.4161/15384047.2014.987021

65. Miao ZF, Adkins-Threats M, Burclaff JR, et al. A metformin-responsive metabolic pathway controls distinct steps in gastric progenitor fate decisions and maturation. Cell Stem Cell. 2020;26(6):910-925.e6. doi:10.1016/j.stem.2020.03.006

66. Koh WP, Wang R, Jin A, et al. Diabetes mellitus and risk of hepatocellular carcinoma: findings from the Singapore Chinese Health Study. Br J Cancer. 2013;108(5):1182-1188. doi:10.1038/ bjc. 2013.25

67. Donadon V, Balbi M, Ghersetti M, et al. Antidiabetic therapy and increased risk of hepatocellular carcinoma in chronic liver disease. World J Gastroenterol. 2009;15(20):2506-2511. doi:10.3748/wjg.15.2506

68. Donadon V, Balbi M, Mas MD, et al. Metformin and reduced risk of hepatocellular carcinoma in diabetic patients with chronic liver disease. Liver Int. 2010;30(5):750-758. doi:10.1111/j.14783231.2010.02223.x

69. Lee MS, Hsu CC, Wahlqvist ML, et al. Type 2 diabetes increases and metformin reduces total, colorectal, liver and pancreatic cancer incidences in Taiwanese: a representative population prospective cohort study of 800,000 individuals. BMC Cancer. 2011;11:20. doi:10.1186/1471-2407-11-20

70. Jang WI, Kim MS, Lim JS, et al. Survival advantage associated with metformin usage in hepatocellular carcinoma patients receiving radiotherapy: a propensity score matching analysis. Anticancer Res. 2015;35(9):5047-5054.

71. Das BK, Choukimath SM, Gadad PC. Asarone and metformin delays experimentally induced hepatocellular carcinoma in diabetic milieu. Life Sci. 2019;230:10-18. doi:10.1016/j. lfs.2019.05.046

72. Shankaraiah RC, Callegari E, Guerriero P, et al. Metformin prevents liver tumourigenesis by attenuating fibrosis in a transgenic mouse model of hepatocellular carcinoma. Oncogene. 2019;38 (45):7035-7045. doi:10.1038/s41388-019-0942-Z

73. Ben $\mathrm{Q}, \mathrm{Xu} \mathrm{M}$, Ning $\mathrm{X}$, et al. Diabetes mellitus and risk of pancreatic cancer: a meta-analysis of cohort studies. Eur J Cancer. 2011;47(13):1928-1937. doi:10.1016/j. ejca.2011.03.003

74. Rieken M, Xylinas E, Kluth L, et al. Diabetes mellitus without metformin intake is associated with worse oncologic outcomes after radical nephroureterectomy for upper tract urothelial carcinoma. Eur J Surg Oncol. 2014;40(1):113-120. doi:10.1016/ j.ejso.2013.09.016 
75. Ren HB, Yu T, Liu C, et al. Diabetes mellitus and increased risk of biliary tract cancer: systematic review and meta-analysis. Cancer Causes Control. 2011;22(6):837-847. doi:10.1007/ s10552-011-9754-3

76. Larsson SC, Wolk A. Diabetes mellitus and incidence of kidney cancer: a meta-analysis of cohort studies. Diabetologia. 2011;54 (5):1013-1018. doi:10.1007/s00125-011-2051-6

77. Dilokthornsakul $\mathrm{P}$, Chaiyakunapruk N, Termrungruanglert W, et al. The effects of metformin on ovarian cancer: a systematic review. Int $J$ Gynecol Cancer. 2013;23(9):1544-1551. doi:10.1097/IGC.0b013e3182a80a21

78. Lin HC, Kachingwe BH, Lin HL, et al. Effects of metformin dose on cancer risk reduction in patients with type 2 diabetes mellitus: a 6-year follow-up study. Pharmacotherapy. 2014;34(1):36-45. doi:10.1002/phar.1334

79. Tseng $\mathrm{CH}$. Metformin and endometrial cancer risk in Chinese women with type 2 diabetes mellitus in Taiwan. Gynecol Oncol. 2015;138(1):147-153. doi:10.1016/j.ygyno.2015.03.059

80. Lee DY, Yu JH, Park S, et al. The influence of diabetes and antidiabetic medications on the risk of pancreatic cancer: a nationwide population-based study in Korea. Sci Rep. 2018;8 (1):9719. doi:10.1038/s41598-018-27965-2

81. Srivastava SP, Goodwin JE. Cancer biology and prevention in diabetes. Cells. 2020;9(6):1380. doi:10.3390/cells9061380

82. Stevens RJ, Ali R, Bankhead CR, et al. Cancer outcomes and all-cause mortality in adults allocated to metformin: systematic review and collaborative meta-analysis of randomised clinical trials. Diabetologia. 2012;55(10):2593-2603. doi:10.1007/ s00125-012-2653-7

83. TOh TK, Song IA. Metformin use and the risk of cancer in patients with diabetes: a nationwide sample cohort study. Cancer Prev Res. 2020;13(2):195-202. doi:10.1158/1940-6207. CAPR-19-0427

84. García-Jiménez C, García-Martínez JM, Chocarro-Calvo A, et al. A new link between diabetes and cancer: enhanced WNT/ $\beta$ catenin signaling by high glucose. Mol Endocrinol. 2013;52(1): R51-66. doi:10.1530/JME-13-0152

85. Pollak M. Insulin and insulin-like growth factor signalling in neoplasia. Nat Rev Cancer. 2008;8(12):915-928. doi:10.1038/ nrc2536

86. Pryor R, Cabreiro F. Repurposing metformin: an old drug with new tricks in its binding pockets. Biochem J. 2015;471 (3):307-322. doi:10.1042/BJ20150497

87. Sui X, Xu Y, Wang X, et al. Metformin: a novel but controversial drug in cancer prevention and treatment. Mol Pharm. 2015;12 (11):3783-3791. doi:10.1021/acs.molpharmaceut.5b00577

88. Li M, Hu X, Xu Y, et al. A possible mechanism of metformin in improving insulin resistance in diabetic rat models Int J Endocrinol. 2019;2019:3248527. doi:10.1155/2019/3248527

89. Mieno MN, Sawabe M, Tanaka N, et al. Significant association between hypolipoproteinemia(a) and lifetime risk of cancer: an autopsy study from a community-based Geriatric Hospital. Cancer Epidemiol. 2014;38(5):550-555. doi:10.1016/j. canep.2014.07.013

90. Win AK, Macinnis RJ, Hopper JL, et al. Risk prediction models for colorectal cancer: a review. Cancer Epidemiol Biomarkers Prev. 2012;21(3):398-410. doi:10.1158/1055-9965

91. Liu CS, Hsu HS, Li CI, et al. Central obesity and atherogenic dyslipidemia in metabolic syndrome are associated with increased risk for colorectal adenoma in a Chinese population. BMC Gastroenterol. 2010;10:51. doi:10.1186/1471-230X-10-51

92. Nelson ER, Chang CY, McDonnell DP. Cholesterol and breast cancer pathophysiology. Trends Endocrinol Metab. 2014;25 (12):649-655. doi:10.1016/j.tem.2014.10.001
93. Dubois V, Delort L, Billard H, et al. Breast cancer and obesity: in vitro interferences between adipokines and proangiogenic features and /or antitumor therapies? PLoS One. 2013;8(3):e58541. doi:10.1371/journal.pone.0058541

94. Geerling JJ, Boon MR, van der Zon GC, et al. Metformin lowers plasma triglycerides by promoting VLDL-triglyceride clearance by brown adipose tissue in mice. Diabetes. 2014;63(3):880-891. doi:10.2337/db13-0194

95. Zhou G, Myers R, Li Y, et al. Role of AMP-activated protein kinase in mechanism of metformin action. J Clin Invest. 2001;108 (8):1167-1174. doi:10.1172/JCI13505

96. Zang M, Zuccollo A, Hou X, et al. AMP-activated protein kinase is required for the lipid lowering effect of metformin in insulin-resistant human HepG2 cells. J Biol Chem. 2004;279 (46):47898-47905. doi:10.1074/jbc.M408149200

97. Lv Z, Guo Y. Metformin and Its Benefits for Various Diseases. Front Endocrinol (Lausanne). 2020;11:191. doi:10.3389/ fendo.2020.00191

98. Elia I, Haigis MC. Metabolites and the tumour microenvironment: from cellular mechanisms to systemic metabolism. Nat Metab. 2021;3(1):21-32. doi:10.1038/s42255-020-003 $17-\mathrm{z}$

99. Mantovani A. Cancer: inflammation by remote control. Nature. 2005;435(7043):752-753. doi:10.1038/435752a

100. Singh N, Baby D, Rajguru JP, et al. Inflammation and cancer. Ann Afr Med. 2019;18(3):121-126. doi:10.4103/aam.aam_56_18

101. Mantovani A, Allavena P, Sica A, et al. Cancer- related inflammation. Nature. 2008;454(7203):436-444. doi:10.1038/ nature 07205

102. Liu Q, Tong D, Liu G, et al. Metformin Inhibits Prostate Cancer Progression by Targeting Tumor-Associated Inflammatory Infiltration. Clin Cancer Res. 2018;24(22):5622-5634. doi:10.1158/1078-0432

103. de Oliveira S, Houseright RA, Graves AL, et al. Metformin modulates innate immune-mediated inflammation and early progression of NAFLD-associated hepatocellular carcinoma in zebrafish. $J$ Hepatol. 2019;70(4):710-721. doi:10.1016/j. jhep.2018.11.034

104. Brown JC, Zhang S, Ligibel JA, et al. A meyerhardt. effect of exercise or metformin on biomarkers of inflammation in breast and colorectal cancer: a randomized trial. Cancer Prev Res. 2020;13(12):1055-1062. doi:10.1158/1940-6207

105. Crusz SM, Balkwill FR. Inflammation and cancer: advances and new agents. Nat Rev Clin Oncol. 2015;12(10):584-596. doi:10.1038/nrclinonc.2015.105

106. Moiseeva O, Deschênes-Simard X, St-Germain E, et al. Metformin inhibits the senescence-associated secretory phenotype by interfering with IKK/NF- $\mathrm{KB}$ activation. Aging Cell. 2013;12 (3):489-498. doi:10.1111/acel.12075

107. Rokavec M, Öner MG, Li H, et al. IL-6R//miR-34a feedback loop promotes EMT-mediated colorectal cancer invasion and metastasis. J Clin Invest. 2014;124(4):1853-1867. doi:10.1172/ JCI73531

108. Kurelac I, Umesh Ganesh N, Iorio M, et al. The multifaceted effects of metformin on tumor microenvironment. Semin Cell Dev Biol. 2020;98:90-97. doi:10.1016/j.semcdb.2019.05.010

109. Elgendy M, Cirò M, Hosseini A, et al. Combination of hypoglycemia and metformin impairs tumor metabolic plasticity and growth by modulating the PP2A-GSK3b-MCL-1 Axis. Cancer Cell. 2019;35(5):798-815.e5. doi:10.1016/j. ccell.2019.03.007

110. Maan M, Peters JM, Dutta M, et al. Lipid metabolism and lipophagy in cancer. BiochemBiophys Res Commun. 2018;504 (3):582-589. doi:10.1016/j.bbrc.2018.02.097 
111. Zhao Y, Li H, Zhang Y, et al. Oncoprotein HBXIP modulates abnormal lipid metabolism and growth of breast cancer cells by activating the LXRs/ SREBP-1c/FAS signaling cascade. Cancer Res. 2016;76(16):4696-4707. doi:10.1158/0008-5472

112. Ibáñez L, De Zegher F. Flutamide-metformin therapy to reduce fat mass in hyperinsulinemic ovarian hyperandrogenism: effects in adolescents and in women on third-generation oral contraception. $J$ Clin Endocrinol Metab. 2003;88 (10):4720-4724. doi:10.1210/jc.2003-030117

113. Tebbe C, Chhina J, Dar SA, et al. Metformin limits the adipocyte tumor-promoting effect on ovarian cancer. Oncotarget. 2014;5 (13):4746-4764. doi:10.18632/oncotarget.2012

114. Ye J, Chen K, Qi L, et al. Metformin suppresses hypoxia- induced migration via the HIF-1 $\alpha$ /VEGF pathway in gallbladder cancer in vitro and in vivo. Oncol Rep. 2019;41(6):3587. doi:10.3892/ or.2019.7101

115. Wang J, Li G, Wang Y, et al. Suppression of tumor angiogenesis by metformin treatment via a mechanism linked to targeting of HER2/HIF-1 $\alpha$ /VEGF secretion axis. Oncotarget. 2015;6 (42):44579-44592. doi:10.18632/oncotarget.6373

116. Orecchioni S, Reggiani F, Talarico G, et al. The biguanides metformin and phenformin inhibit angiogenesis, local and metastatic growth of breast cancer by targeting both neoplastic and microenvironment cells. Int $J$ Cancer. 2015;136(6):E534-44. doi:10.1002/ijc. 29193

117. Kalluri R. The biology and function of fibroblasts in cancer. Nat Rev Cancer. 2016;16(9):582-598. doi:10.1038/nrc.2016.73

118. Xu S, Yang Z, Jin P, et al. Metformin suppresses tumor progression by inactivating stromal fibroblasts in ovarian cancer. Mol Cancer Ther. 2018;17(6):1291-1302. doi:10.1158/1535-7163

119. Zhou X, Chen J, Yi G, et al. Metformin suppresses hypoxia-induced stabilization of HIF-1alpha through reprogramming of oxygen metabolism in hepatocellular carcinoma. Oncotarget. 2016;7(1):873-884. doi:10.18632/oncotarget.6418

120. Kim J, Kwak HJ, Cha JY, et al. Metformin suppresses lipopolysaccharide (LPS)-induced inflammatory response in murine macrophages via activating transcription factor-3 (ATF-3) induction. $J$ Biol Chem. 2014;289(33):23246-23255. doi:10.1074/jbc.M114.577908

121. Wang JC, Sun X, Ma Q, et al. Metformin's antitumour and antiangiogenic activities are mediated by skewing macrophage polarization.J. Cell Mol Med. 2018;22(8):3825-3836. doi:10.1111/jcmm.13655

122. Nishino $\mathrm{M}$, Ramaiya $\mathrm{NH}$, Hatabu $\mathrm{H}$, et al. Monitoring immune-checkpoint blockade: response evaluation and biomarker development. Nat Rev Clin Oncol. 2017;14(11):655-668. doi:10.1038/nrclinonc.2017.88

123. Eikawa S, Nishida M, Mizukami S, et al. Immune-mediated antitumor effect by type 2 diabetes drug, metformin. Proc Natl Acad Sci U S A. 2015;112(6):1809-1814. doi:10.1073/ pnas. 1417636112

124. Li L, Wang L, Li J, et al. Metformin-induced reduction of CD39 and CD73 blocks myeloid-derived suppressor cell activity in patients with ovarian. Cancer Cancer Res. 2018;78 (7):1779-1791. doi:10.1158/0008-5472

125. Podhorecka M, Ibanez B, Dmoszyńska A. Metformin - its potential anti-cancer and anti-aging effects. PostepyHig Med Dosw. 2017;71:170-175. doi:10.5604/01.3001.0010.3801

126. Gwinn DM, Shackelford DB, Egan DF, et al. AMPK phosphorylation of raptor mediates a metabolic checkpoint. Mol Cell. 2008;30(2):214-226. doi:10.1016/j.molcel.2008.03.003

127. Blandino G, Valerio M, Cioce M, et al. Metformin elicits anticancer effects through the sequential modulation of DICER and c-MYC. Nat Commun. 2012;3:865. doi:10.1038/ncomms1859

128. Corominas-Faja B, Quirantes-Piné R, Oliveras-Ferraros C, et al. Metabolomic fingerprint reveals that metformin impairs one-carbon metabolism in a manner similar to the antifolate class of chemotherapy drugs. Aging. 2012;4(7):480-498. doi:10.18632/aging.100472
129. Engeland K. Cell cycle arrest through indirect transcriptional repression by p53: i have a DREAM. Cell Death Differ. 2018;25(1):114-132. doi:10.1038/cdd.2017.172

130. Yudhani RD, Astuti I, Mustofa M, et al. Metformin Modulates Cyclin D1 and P53 Expression to Inhibit Cell Proliferation and to Induce Apoptosis in Cervical Cancer Cell Lines. Asian Pac J Cancer Prev. 2019;20(6):1667-1673. doi:10.31557/APJCP.2019.20.6.1667

131. Yazdani R, Fatholahi M, Ganjalikhani-Hakemi M, et al. Role of apoptosis in common variable immunodeficiency and selective immunoglobulin A deficiency. Mol Immunol. 2016;71:1-9. doi:10.1016/j.molimm.2015.12.016

132. Kunac N, Šundov Ž, Vilović K. Apoptosis as a prognostic factor in colorectal carcinoma: comparison of TUNEL method and immunohistochemical expression of Caspase-3. ApplImmunohistochem Mol Morphol. 2019;27(3):e22-e27. doi:10.1097/PAI.0000000000000623

133. Wang Y, Xu W, Yan Z, et al. Metformin induces autophagy and G0/G1 phase cell cycle arrest in myeloma by targeting the AMPK/mTORC1 and mTORC2 pathways. J Exp Clin Cancer Res. 2018;37(1):63. doi:10.1186/s13046-018-0731-5

134. Liu S, Yue C, Chen H, et al. Metformin Promotes Beclin1-Dependent Autophagy to Inhibit the Progression of Gastric Cancer. Onco Targets Ther. 2020;13:4445-4455. doi:10.2147/OTT.S242298

135. Zheng Z, Bian Y, Zhang Y, et al. Metformin activates AMPK/SIRT1/ $\mathrm{NF}-\mathrm{\kappa B}$ pathway and induces mitochondrial dysfunction to drive caspase3/GSDME-mediated cancer cell pyroptosis. Cell Cycle. 2020;19(10):1089-1104. doi:10.1080/15384101.2020.1743911

136. Wang L, Li K, Lin X, et al. Metformin induces human esophageal carcinoma cell pyroptosis by targeting the miR-497/PELP1 axis. Cancer Lett. 2019;450:22-31. doi:10.1016/j.canlet.2019.02.014

137. Feng $\mathrm{Y}, \mathrm{Ke} \mathrm{C}$, Tang Q, et al. Metformin promotes autophagy and apoptosis in esophageal squamous cell carcinoma by downregulating Stat3signaling. Cell Death Dis. 2014;5(2):e1088. doi:10.1038/cddis.2014.59

138. Poli G, Cantini G, Armignacco R, et al. Metformin as a new anti-cancer drug in adrenocortical carcinoma. Oncotarget. 2016;7 (31):49636-49648. doi:10.18632/oncotarget.10421

139. YShi Y, He Z, Jia Z, et al. Inhibitory effect of metformin combined with gemcitabine on pancreatic cancer cells in vitro and in vivo. Mol Med Rep. 2016;14(4):2921-2928. doi:10.3892/ mmr.2016.5592

140. Wu Y, Gao WN, Xue YN, et al. SIRT3 aggravates metformin-induced energy stress and apoptosis in ovarian cancer cells. Exp Cell Res. 2018;367(2):137-149. doi:10.1016/j. yexcr.2018.03.030

141. Sun R, Zhai R, Ma C, et al. Combination of aloin and metformin enhances the antitumor effect by inhibiting the growth and invasion and inducing apoptosis and autophagy in hepatocellular carcinoma through PI3K/AKT/mTOR pathway. Cancer Med. 2020;9(3):1141-1151. doi:10.1002/cam4.2723

142. Li B, Zhou P, Xu K, et al. Metformin induces cell cycle arrest, apoptosis and autophagy through ROS/JNK signaling pathway in human osteosarcoma. Int $J$ Biol Sci. 2020;16(1):74-84. doi:10.7150/ijbs. 33787

143. Yenmiş G, Beşli N, Yaprak Saraç E, et al. Metformin promotes apoptosis in primary breast cancer cells by downregulation of cyclin D1 and upregulation of P53 through an AMPK-alpha independent mechanism. Turk J Med Sci. 2021;51(2):826-834. doi:10.3906/sag-1908-112

144. Park JH, Kim YH, Park EH, et al. Effects of metformin and phenformin on apoptosis and epithelial- mesenchymal transition in chemoresistant rectal cancer. Cancer Sci. 2019;110 (9):2834-2845. doi:10.1111/cas.14124 
Diabetes, Metabolic Syndrome and Obesity: Targets and Therapy is an international, peer-reviewed open-access journal committed to the rapid publication of the latest laboratory and clinical findings in the fields of diabetes, metabolic syndrome and obesity research. Original research, review, case reports, hypothesis formation, expert opinion and commentaries are all considered for publication. The manuscript management system is completely online and includes a very quick and fair peer-review system, which is all easy to use. Visit http://www.dovepress.com/testimonials.php to read real quotes from published authors. 